or using other stimuli, i.e. IL-4 and TNF- $\alpha$, indicating a specific function for the rs3761847 polymorphism in unstimulated and LPS+IFN $\gamma$-activated monocytes. Conclusions: Our findings suggest that there is no relationship between invasive capacity of RASF or expression of TRAF1-C5 genes and genotype at rs3761847. In contrast, we report an association of the rs3761847 genotype and TRAF1 expression in monocytes. These data underline the importance of studying genotype-phenotype associations in the different cell types relevant for RA pathogenesis.

Disclosure of Interest: None declared

DOI: 10.1136/annrheumdis-2017-eular.6066

\section{THU0015 INVESTIGATION OF JUVENILE IDIOPATHIC ARTHRITIS (JIA) IN GREECE: NEW SUSCEPTIBILITY LOCI}

M.I. Zervou ${ }^{1}$, D.G. Dimopoulou ${ }^{2}$, E. Eliopoulos ${ }^{3}$, M. Trachana ${ }^{4}$

P. Pratsidou-Gkertsi ${ }^{4}$, A. Andreou ${ }^{3}$, A. Garyfallos ${ }^{2}$, G.N. Goulielmos ${ }^{1} .{ }^{1}$ Medical School, University of Crete, Heraklion, Crete, ${ }^{2} 4$ th Department of Internal Medicine, Hippocratio Hospital, Aristotle University of Thessaloniki, Thessaloniki; ${ }^{3}$ Biotechnology, Agricultural University of Crete, Athens; ${ }^{4} 1$ st Department of Pediatrics, Aristotle University of Thessaloniki, Thessaloniki, Greece

Background: Juvenile idiopathic arthritis (JIA) is an autoimmune disease characterized by persistent chronic arthritis, in which both genetic and environmental components are involved [1]. Different genetic variations have been reported as risk factors for JIA, but a difficulty of the replication of results in different ethnic backgrounds indicates the existence of an ethnic heterogeneity of genetic factors for JIA.

Objectives: We sought to validate three single nucleotide polymorphisms (SNPs), namely PTPRC (rs10919563), TYK2 (rs34536443) and PRKCQ (rs4750316), previously found to be associated with JIA [2-4], and to investigate whether the 27-bp VNTR polymorphism on intron 4 of eNOS, which is associated with various autoimmune diseases so far [5], is associated with risk for JIA in Greece.

Methods: The sample set consisted of $125 \mathrm{JIA}$ patients and 221 healthy controls from Northern Greece. Genotyping of the three SNPs was performed with Taqman primer-probe sets, using a Real-Time PCR platform (Applied Biosystems, ViiA ${ }^{\mathrm{TM}}$ 7 Real-Time PCR System), while eNOS VNTR polymorphism was genotyped by PCR. Odds ratios (OR) and $95 \%$ confidence intervals $(\mathrm{Cl})$ were calculated and the statistical difference in allele distribution was assessed by means of $x^{2}$ test or Fisher's exact test. Bioinformatic analysis was performed using BlastP, Pymol and Maestro and Desmond (Schrodinger Inc.).

Results: A case-control association study was conducted enrolling 4 successfully genotyped markers. eNOS only was found to be associated with JIA. Genotype $\mathrm{a} / \mathrm{a}$ and allele "a" were more common in individuals with JIA than in controls $(p<0.0001, O R=0.15,95 \% \mathrm{Cl} 0.065-0.37$ and $p<0.0001, \mathrm{OR}=0.34,95 \% \mathrm{Cl}$ $0.23-0.49$, respectively). No associations with JIA were detected for TYK2, $P T P R C$ or $P R K C Q$. Aiming to investigate the structural consequences and the structure/function relationships accompanying the Pro1104 to Ala (rs34536443) mutation on TYK2 protein, bioinformatics analysis was performed. Combining 3D-modeling and Molecular Dynamics simulations we have noted changes in structural flexibility, affecting the functionality of the kinase domain of TYK2.

Conclusions: This study demonstrated for the first time that eNOS VNTR polymorphism is associated with susceptibility to JIA, thus suggesting that the risk allele "a" may confer susceptibility to clinically distinct disorders. Apart from the previously reported evidence for the role of PTPRC rs10919563, PRKCQ rs4750316 and TYK2 rs34536443 in an increased risk for JIA, our results demonstrate no association of these genes with JIA in the Greek population. However, the lack of association of PTPRC SNP with JIA is in line with previous data reported from cohorts in US and Australia. Taken together, the results highlight the importance of comparative studies in different populations, considering that replication of previously identified markers is paramount to determine which SNPs represent true risk loci, thus pointing towards key disease pathways which warrant further study.

References:

[1] Ravelli and Martini (2007). Lancet 369:767-78.

[2] Hinks et al (2010). Ann Rheum Dis 69:1049-53.

[3] Hinks et al. (2012). Ann Rheum Dis 71:1117-21.

[4] Hinks et al (2013). Nat Genet 45: 664-9.

[5] Vazgiourakis et al (2007). Lupus 16:867-74.

Disclosure of Interest: None declared

DOI: 10.1136/annrheumdis-2017-eular.2258

\section{THU0016 A COMPREHENSIVE CONTRIBUTION OF GENES OF THE HYPOXIA INDUCIBLE FACTOR-1 ALPHA SIGNALING PATHWAY TO KNEE OSTEOARTHRITIS SUSCEPTIBILITY}

J. Fernandez-Torres $^{1,2}$, G.A. Martínez-Nava ${ }^{1}$, A. López-Reyes ${ }^{1}$,

Y. Zamudio-Cuevas ${ }^{1}$, D. Clavijo-Cornejo ${ }^{1}$, K. Martínez-Flores ${ }^{1}$,

M.C. Gutiérrez-Ruíz ${ }^{2}$, L.E. Gómez-Quiroz ${ }^{2}$, C. Pineda ${ }^{1} .{ }^{1}$ Laboratorio de Líquido Sinovial, Instituto Nacional de Rehabilitacion; ${ }^{2}$ Cellular Physiology Laboratory, Universidad Autónoma Metropolitana-Iztapalapa, Mexico City, Mexico

Background: The hallmark of osteoarthritis (OA) is the breakdown of articular cartilage. Articular cartilage is an avascular tissue, and this generates a hypoxic microenvironment. Hypoxia inducible factor $-1 \alpha(\mathrm{HIF}-1 \alpha)$ is the main transcriptional regulator of cellular and developmental response to hypoxia.

Objectives: The present study was designed to investigate whether genetic polymorphisms of the HIF-1 $\alpha$ signaling pathway are involved in the development of knee OA.

Methods: A total of 243 unrelated Mexican-mestizo individuals comprising 93 knee OA patients and 150 healthy controls were recruited into the study. 42 genetic polymorphisms from 22 genes involved in the HIF-1 $\alpha$ signaling pathway (PIK3R1, AKT2, GSK3B, IL6, AGER, HIF1A, EGLN1, VHL, HIF1AN, VEGFA, EPO, NOS2, NOS3, IGF1, EGF, EDN1, MMP1, MMP3, MMP13, CA, COL2A1, COL3A1) were genotyped in cases and controls using TaqMan-based allelic discrimination assays.

Results: After adjusting for age, sex and admixture, significant associations with knee OA were found for 7 SNPs in the case-control study. The following genotypes and alleles were associated with protection against $\mathrm{OA}$ : the CT genotype of the HIF1AN rs 11190613 polymorphism (OR=0.44, 95\% $\mathrm{Cl}=0.19-1.0$, $P=0.05$ ); the AA genotype of the VEGFA rs 1570360 polymorphism (OR $=0.14$, $95 \% \mathrm{Cl}=0.02-0.69, P=0.016)$; the GT genotype and T allele of the VEGFA rs729761 polymorphism $(\mathrm{OR}=0.47,95 \% \mathrm{Cl}=0.22-1.0, P=0.05$; and $\mathrm{OR}=0.51$, $95 \% \mathrm{Cl}=0.27-0.97, P=0.041$, respectively); the GA genotype of the COL2A1 rs 1793953 polymorphism (OR=0.40, 95\% $\mathrm{Cl}=0.20-0.79, P=0.008)$; and the $\mathrm{GG}$ genotype and $\mathrm{G}$ allele of the CKM rs 4884 polymorphism $(\mathrm{OR}=0.34,95 \% \mathrm{Cl}=0.14-$ $0.84, P=0.019$; and $\mathrm{OR}=0.51,95 \% \mathrm{Cl}=0.32-0.82$, respectively). Otherwise, the CT genotype of the COL3A1 rs2138533 polymorphism (OR=2.89, 95\% $\mathrm{Cl}=1.28-6.5$, $P=0.01$ ); and the GA genotype of the IGF1 rs35767 polymorphism (OR=2.22, 95\% $\mathrm{Cl}=1.11-4.43, P=0.024$ ) were associated with an increased risk of OA. However, by using of epistatic interactions between HIF-1 $\alpha$ pathway polymorphisms, we found that the gene-gene interaction had a synergistic effect over the estimated OR-values (see table).

\begin{tabular}{|c|c|c|c|c|}
\hline a & $\mathrm{b}$ & $\mathrm{OR}_{\mathrm{i}}$ & $\mathrm{OR}_{\mathrm{c}}{ }^{*}$ & $P_{\mathrm{int}}$ \\
\hline VEGFA rs 1570360 & COL3A1 rs2138533 & & & \\
\hline \multirow[t]{3}{*}{ GG } & $\mathrm{CC}$ & 1 & & 0.027 \\
\hline & CT & 2.89 & 4.51 & \\
\hline & TT & 1.24 & 11.1 & \\
\hline COL3A1 rs2138533 & IGF1 rs35767 & & & \\
\hline \multirow[t]{2}{*}{$\mathrm{T}$} & G & 1 & & 0.037 \\
\hline & A & 1.49 & 3.26 & \\
\hline CKM rs 4884 & COL3A1 rs2138533 & & & \\
\hline \multirow[t]{2}{*}{ A } & $\mathrm{C}$ & 1 & & 0.036 \\
\hline & $\mathrm{T}$ & 1.27 & 4.08 & \\
\hline COL2A1 rs1793953 & HIF1AN rs11190613 & & & \\
\hline \multirow[t]{2}{*}{ A } & $\mathrm{T}$ & 1 & & 0.05 \\
\hline & C & 0.71 & 0.35 & \\
\hline
\end{tabular}

$\mathrm{OR}_{\mathrm{i}}=$ initial OR-value; $\mathrm{OR}_{\mathrm{c}}{ }^{*}=$ combined OR-value obtained by "b" column interaction with "a" column; $P_{\text {int }}=P$-value of the intreraction.

Conclusions: In this study we could observe that the gene-gene interaction of the HIF-1 $\alpha$ signaling pathway highly increases the risk of developing $O A$, with the exception of COL2A1 and HIF1AN interaction which had a protective role against $O A$. Further studies are needed to validate this results.

References:

[1] Fernández-Torres J, et al. Polymorphic variation of hypoxia inducible factor-1 A (HIF1A) gene might contribute to the development of knee osteoarthritis: a pilot study. BMC Musculoskelet Disord 2015; 16:218.

[2] Rodríguez-Fontanela $\mathrm{C}$, et al. Assessment of osteoarthritis candidate genes in a meta-analysis of nine genome-wide association studies. Arthritis Rheumatol 2014; 66:940-949.

Disclosure of Interest: None declared

DOI: 10.1136/annrheumdis-2017-eular.2131

\section{THU0017 COMBINATION OF EGFR AND BLYS GENE EXPRESSION IN LUPUS NEPHRITIS}

L.A. Mas ${ }^{1,2}$, S. Retamozo ${ }^{2,3}$, F. Bonisconti ${ }^{1,2}$, E.V. Palomino ${ }^{1,2}$, J.P. Pirola ${ }^{2,3}$, V. Saurit $^{2,3}$, A. Alvarellos ${ }^{2,3}$, T. Alvarellos ${ }^{1,2}{ }^{1}$ Immunogenetics, Hospital Privado. Universitario de Córdoba; ${ }^{2}$ Instituto Universitario de Ciencias Biomédicas de Córdoba; ${ }^{3}$ Rheumatology, Hospital Privado. Universitario de Córdoba, Cordoba, Argentina

Background: Lupus nephritis (LN) is a severe complication of Systemic Lupus Erythematosus (SLE). Non-invasive biomarkers are needed for diagnosis of LN and to identify patients at risk of a renal flare (1). Thus the presence of biomarkers associated with inflammation, tissue damage or cell activation in the urine of patients with $L N$ may be a useful tool in the evaluation of LN patients.

The glomerular filtration rate (GFR) is considered the best overall index of renal function in health and disease. Because GFR is difficult to measure in clinical practice, most clinicians estimate the GFR (eGFR) from the serum creatinine concentration (2).

B Lymphocyte Stimulator (BLyS) is a cytokine that fosters B cell activation, antibody production, B cell - T cell interaction and plasma cell survival. These events have been demonstrated to play a role in patients with LN (3).

Objectives: We evaluated urinary levels of BLyS as biomarker for LN and their relationship with eGFR. 
Methods: Urine samples $(\mathrm{n}=86)$ were obtained from $\mathrm{LN}$ patients and classified in two groups: patients with eGFR $>60$ (GFRhigh, $n=68,62 F / 6 M$, age: $34.07 \pm 13.24$ ) and patients with eGFR $\leq 60$ (GFRlow, $n=18,14 F / 4 M$, age: $35.22 \pm 13.76$ ). RNA from urine samples was isolated using TRIzol-Chloroform technique and then reverse-transcribed using random primers. Levels of BLyS expression were evaluated using Quantitative Real Time PCR (QPCR). All amplifications were carried out in duplicate and threshold cycle $\left(C_{t}\right)$ scores were averaged for calculations of relative expression values. The $C_{t}$ scores were normalized against $\mathrm{C}_{t}$ scores by subtracting the corresponding $\beta 2$ Microglobuline $(\beta 2 \mathrm{M})$ control, or $\mathrm{DCt}=\mathrm{C}_{\mathrm{t}, \text { gene }}-\mathrm{C}_{\mathrm{t}, \mathrm{B} 2 \mathrm{M}}$. To test for differential gene expression between groups, a two sample t-test was performed to compare the DCt in the two groups.

Results: DCt is inversely proportional to BLyS's expression. We evaluated data from $\triangle \mathrm{Ct}$ analysis observing that mRNA levels of BLyS in eGFRlow $(6.193 \pm 1.787)$ were higher than those from eGFRhigh $(7.564 \pm 2.326)$, with a statistically significant difference between groups $(p=0.0288)$.

\begin{tabular}{lccc}
\hline & eGFRlow & eGFRhigh & \\
\hline BLyS $(\Delta \mathrm{Ct})$ & $6.193 \pm 1.787$ & $7.564 \pm 2.326$ & $\mathrm{p}=0.0288$ \\
\hline
\end{tabular}

Conclusions: In the present cross-sectional study, increased levels of BLyS were observed in patients with eGFR $\leq 60$. These gene expression results might be linked to $B$ cell activation and proliferation in kidney and thus in urine samples. Combination of eGFR and BLyS appears to be a good biomarker.

\section{References:}

[1] Rahman A. Can measuring urinary biomarkers improve the management of lupus nephritis? Arthritis Research \& Therapy 2012, 14:127.

[2] Levey AS, Bosch JP, Lewis JB, Greene T, Rogers N, Roth D. A more accurate method to estimate glomerular filtration rate from serum creatinine: a new prediction equation. Modification of Diet in Renal Disease Study Group. Ann Intern Med. 1999 Mar 16; 130 (6):461-70.

[3] Phatak S, Chaurasia S, Mishra SK, Gupta R, Agrawal V, Aggarwal A, Misra R. Urinary B cell activating factor (BAFF) and a proliferation inducing ligand (APRIL): potential biomarkers of active lupus nephritis. Clin Exp Immunol. 2016. Epub ahead of print.

Disclosure of Interest: None declared

DOI: 10.1136/annrheumdis-2017-eular.4793

\section{THU0018 ANGIOTENSINOGEN AS A MARKER OF INJURY IN LUPUS NEPHRITIS}

$\underline{\text { L.A. Mas }}^{1,2}$, S. Retamozo ${ }^{2,3}$, M.J. Haye Salinas ${ }^{3}$, V. Saurit 2,3 , E.V. Palomino ${ }^{1,2}$ J.L. De la Fuente ${ }^{2,4}$, M. Angelina 2,5 , J.P. Pirola ${ }^{2,3}$, A. Alvarellos $^{2,3}$,

T. Alvarellos ${ }^{1} .{ }^{1}$ Immunogenetics, Hospital Privado. Universitario de Córdoba;

${ }^{2}$ Instituto Universitario de Ciencias Biomédicas de Córdoba; ${ }^{3}$ Rheumatology;

${ }^{4}$ Nephrology, Hospital Privado. Universitario de Córdoba; ${ }^{5}$ Nephrology, Hospital

Raúl Ferreyra, Cordoba, Argentina

Background: Lupus Nephritis (LN) is one of the most severe forms of systemic lupus erythematosus (SLE) (1). Angiotensinogen (AGT) gene encodes the only glycoprotein known to be a precursor of the vasopresor angiotensin II (Ang II). Ang II is also a growth factor and a profibrogenic cytokine (2). In kidney transplantation AGT has been founded down expressed in biopsies with chronic allograft dysfunction (3). In LN, AGT deserves evaluation.

Objectives: To investigate AGT expression in biopsies and urines from LN patients.

Methods: 32 biopsies/urines paired from 32 LN patients was included. Kidney biopsies were evaluated according to the ISN/RPS classification system. Levels of AGT were evaluated using Quantitative Real Time PCR. Threshold cycle $\left(C_{t}\right)$ scores were averaged for calculations of relative expression values. The $\mathrm{C}_{t}$ scores were normalized against $C_{t}$ scores by subtracting $\beta 2$ Microglobuline control, or $\Delta \mathrm{Ct}=\mathrm{C}_{\mathrm{t} \text { gene }}-\mathrm{C}_{\mathrm{t}, \mathrm{B} 2 \mathrm{M}}$. Data expressed as $\Delta \mathrm{Ct}$ are inversely proportional to gene expression level. Nonparametric Mann Whitney test analysis and Anova with Bonferroni test were performed.

Results: $26(81.3 \%)$ patients were female with a mean age at biopsy time of $31.9 \pm 29$ years. The SLEDAI at the time of biopsy was 10.5 (IQR $0-15.7$ ) and SLICC $\geq 1$ in $13(32.5 \%)$, hypocomplementemia $13 / 31(41.9 \%)$ and positive DNA in $11 / 29(37.9 \%)$ patients. Biopsies from patients with proteinuria $\geq 0.5$ and renal failure $(n=23)$, proteinuria isolated $(n=14), L N$ remission $(n=9)$, renal failure $(n=7)$

Table 1. AGT gene expression in biopsies and urines samples

\begin{tabular}{lccccc}
\hline & $\begin{array}{c}\text { Class I/ } \\
\text { Normal Biopsies } \\
\mathrm{n}=3\end{array}$ & $\begin{array}{c}\text { Class II } \\
\text { Biopsies } \\
\mathrm{n}=6\end{array}$ & $\begin{array}{c}\text { Class IV } \\
\text { Biopsies } \\
\mathrm{n}=12\end{array}$ & $\begin{array}{c}\text { Class V/VI } \\
\text { Biopsies } \\
\mathrm{n}=10\end{array}$ & $\mathrm{p}$ \\
\hline Clt AGT Biopsies* $^{*}$ & 5,57 & 3,67 & 5,34 & $\mathrm{p}$ \\
\hline Ct AGT Urines $^{* *}$ & $(3,60-5,57)$ & $(2,19-5,37)$ & $(4,75-10,93)$ & $(3,45-4,57)$ & 0,02 \\
& 14,11 & 11,19 & 16,77 & 15,06 & 0,01 \\
& $(12,44-14,11)$ & $(9,53-11,59)$ & $(12,88-18,25)$ & $(12,16-17,62)$ & \\
\hline
\end{tabular}

${ }^{*} \mathrm{p}<0,05$ class IV vs II; ${ }^{* *} \mathrm{p}<0,05$ Class IV vs II.

Table 2. AGT gene expression in biopsies according proteinuria levels

\begin{tabular}{lllc}
\hline & Proteinuria $\leq 0,5$ & Proteinuria $>0,5$ & $\mathrm{p}$ \\
\hline$\Delta$ Ct AGT Biopsies & $3,60(3,34-4,41)$ & $4,79(3,73-6,39)$ & 0,04 \\
\hline
\end{tabular}

and nephrotic syndrome $(n=2)$ were performed. The mean value of $\Delta$ Ct AGT gene expression in renal biopsy was 4.50 (IQR $3.51-5.67$ ) and AGT in urine samples was 13.94 (IQR 11.66 - 17.89).

Conclusions: In the present study we found a potential utility of AGT mRNA levels in samples of active vs remission LN patients. Prospective studies are needed for confirming these results.

\section{References:}

[1] Yajuan Li et al. Biomarkers Profiling for Lupus Nephritis. Genomics Proteomics Bioinformatics 11; 158-165, 2013.

[2] Eriguchi $\mathrm{M}$ et al. Assessment of urinary angiotensinogen as a marker of podocyte injury in proteinuric nephropathies. Am J Physiol Renal Physiol 310: F322-F333, 2016

[3] Mas $\mathrm{V}$ et al. Establishing the molecular pathways involved in chronic allograft nephropathy for testing new non-invasive diagnostic markers. Transplantation. 83:448-57, 2007.

Disclosure of Interest: None declared

DOI: 10.1136/annrheumdis-2017-eular.6760

\section{THU0019 FEATURES OF TELOMERE LENGTH DISTRIBUTION ON INDIVIDUAL CHROMOSOMES IN RHEUMATOID ARTHRITIS}

M. Barkovskaya ${ }^{1}$, A. Bogomolov ${ }^{2}$, N. Knauer $^{1}$, E. Blinova ${ }^{1}$, A. Sizikov ${ }^{3}$,

N. Rubtsov ${ }^{2}$, V. Kozlov ${ }^{1} .{ }^{1}$ Laboratory of the Clinical Immunopathology, Research Institute of Fundamental and Clinical Immunology; ${ }^{2}$ Laboratory of the

Morphology and Function of Subcellular Components, Institute of Cytology and Genetics SB RAS; ${ }^{3}$ Department of Clinical Rheumatology, Clinic of Immunopathology, Novosibirsk, Russian Federation

Background: Telomeres are nucleoprotein structures,that protect the ends of chromosomes during cell divisions $[1,2,3]$. Previously it was found, that average telomere length in immune cells is reduced in atopic and autoimmunity disorders. This fact indicates an early immune aging in immune-mediated diseases $[4,5]$. The distribution of telomere repeats on different chromosomes has an individual telomere profile in humans [6] and may be a congenital feature, that accelerates immunosenescence.

Objectives: The purpose of this study was to evaluate the length of telomeres in the arms of individual chromosomes in patients with RA and healthy donors.

Methods: The study included 6 patients with RA and 6 healthy donors (the median age $51.5(50-54)$ and 51.5 (49-53) years respectively). Metaphase spreads obtained from PBMCs were used in this study. Written informed consent was obtained from each person enrolled in the study. At the time of sampling, RA inpatients characterized with acute exacerbation of the disease received treatment at the Clinic of Immunopathology,Novosibirsk. RA was diagnosed by clinicians according to ACR/EULAR 2010. For measurement of the telomere length on individual chromosome arms we used Q-FISH with $\left(\mathrm{C}_{3} \mathrm{TA}_{2}\right)_{3} \mathrm{PNA}$-probe. Inverted DAPI banding was used for chromosome identification according to ISCN 2013. The new MeTeLen software was developed to estimate the telomere repeats relative quantity (http://www.bionet.nsc.ru/en/development/applicationdevelopment/development-of-a-computer/metelen.html) in metaphase images.

Results: When comparing the telomere length, it was found, that telomere on chromosome $16 p$ are shorter in patients with RA than in donors. Since each person has an individual telomere profile, we also analyzed the presence of shortened telomere sequences on individual chromosome arms relative to the average length of telomeres for each subject separately. As a result, patients with RA have a larger number of significantly shortened telomeres than donors (see Table).

\begin{tabular}{lc}
\hline Comparison group & Chromosome arms with shortened telomere repeats \\
\hline Healthy volunteers & $12 p, 19 p, 2 q, 20 q$ \\
Patients with RA & $7 p, 12 p, 16 p, 17 p, 19 p, 2 q, 20 q, 21 q$ \\
\hline
\end{tabular}

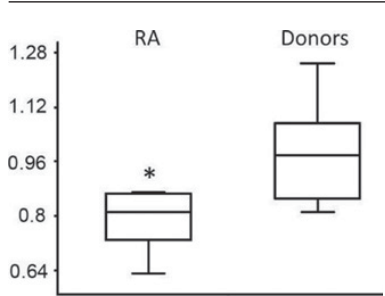

Telomere length on chromosome $16 \mathrm{p}$ (expressed

in relative units) in patients with RA and health

donors. Data are presented as median and

interquartile range, ${ }^{*}$-significant difference

$(\mathrm{p}<0.05$, Mann-Whitney U test).

Conclusions: The revealed features of telomeric profiles of patients with RA may be an indication of a proliferative stress, that occurs as a result of the mass immune cell proliferation in the immunopathology. It can be assumed, that the presence of a great number of shortened telomeres can promote cell death through apoptosis. The observed shortening of the telomere length on chromosome $16 \mathrm{p}$ in RA may be relevant in its pathogenesis. It is known, that telomere shortening can lead to increased gene expression near the telomere DNA region. Thus, in $16 \mathrm{p} 13$ a number of genes is localized, that are associated with RA or may be involved in its development. 